SCOTTÁ, B.A. et al. Nutrição pré e pós-eclosão em aves. PUBVET, Londrina, V. 8, N. 8, Ed. 257, Art. 1702, Abril, 2014.

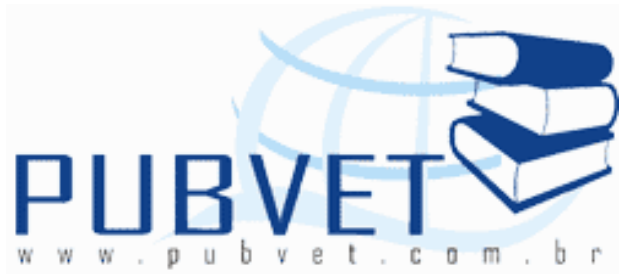

PUBVET, Publicações em Medicina Veterinária e Zootecnia.

\title{
Nutrição pré e pós-eclosão em aves
}

\author{
Bruno Andreatta Scottá ${ }^{1}$, Priscila Furtado Campos $^{1}$, Ana Paula Cardoso \\ Gomide $^{1}$, Carlota Coelho Barroca ${ }^{1}$, Andressa da Silva Formigoni ${ }^{2}$ \\ Mayra Fonseca Zerlotini ${ }^{3}$
}

\begin{abstract}
${ }^{1}$ Doutorando(a) do Programa de Pós-Graduação em Zootecnia da Universidade Federal de Viçosa - UFV.

${ }^{2}$ Doutoranda do Programa de Pós-Graduação em Zootecnia da Universidade Federal de Minas Gerais - UFMG.

3Médica Veterinária
\end{abstract}

\section{Resumo}

Este trabalho teve como objetivo expor as características, vantagens e desvantagens da nutrição pré e pós-eclosão em aves. Na avicultura, várias técnicas têm surgido com o objetivo de melhorar a produção das aves desde a postura dos ovos até o abate dos animais. Dentre essas técnicas a nutrição pré-eclosão é um conceito promissor que visa disponibilizar ao embrião ainda no ovo maior quantidade de nutrientes, podendo levar a um melhor desempenho dos animais após a eclosão. Já a nutrição pós-eclosão tem como objetivo disponibilizar ao animal recém eclodido rápido acesso ao alimento para acelerar a maturação intestinal tanto morfologicamente como fisiologicamente para que não ocorram perdas irreversíveis no desempenho do animal. A nutrição pré-eclosão, mesmo sendo um conceito promissor, apresenta resultados controversos, talvez devido à técnica de aplicação dos 
SCOTTÁ, B.A. et al. Nutrição pré e pós-eclosão em aves. PUBVET, Londrina, V. 8, N. 8, Ed. 257, Art. 1702, Abril, 2014.

nutrientes ou devido aos nutrientes aplicados ou ainda aos níveis de aplicação, sendo necessário que mais trabalhos sejam realizados nessa área. A nutrição pós-eclosão tem se mostrado eficiente na maturação precoce do trato gastrintestinal que mesmo já nascendo anatomicamente completo, o rápido acesso a alimentação sólida acelera o processo de maturação, levando a uma rápida evolução dos enterócitos e maior produção enzimas digestivas.

Palavras-chave: composição do ovo, desenvolvimento embrionário, nutrição no ovo

\title{
Nutrition pre and post-hatching in poultry
}

\begin{abstract}
This study aimed to expose the features, advantages and disadvantages of nutrition pre and post-hatching poultry. In poultry several techniques have emerged with the aim of improving the production of birds from laying eggs until the slaughter of animals. Among these techniques nutrition pre-hatching is a promising concept that aims to provide the embryo in the egg even greater amount of nutrients, which can lead to a better performance of the animals after hatching. Already nutrition after hatching aims to provide the animal newly hatched quick access to food to accelerate intestinal maturation both morphologically and physiologically to prevent any irreversible losses in animal performance. The nutrition pre-hatching even as a promising concept, presents conflicting results, perhaps due to the application technique due to the nutrient or nutrients applied or the application level, necessitating more work is being done in this area. Nutrition after hatching has been shown effective in early maturation of the gastrointestinal tract that even now born anatomically complete, quick access to solid food accelerates the maturation process, leading to a quickly evolution of enterocytes and increased production of digestive enzymes.
\end{abstract}

Keywords: egg composition, embryonic development, nutrition in egg 
SCOTTÁ, B.A. et al. Nutrição pré e pós-eclosão em aves. PUBVET, Londrina, V. 8, N. 8, Ed. 257, Art. 1702, Abril, 2014.

\section{1 - Introdução}

$\mathrm{Na}$ avicultura várias técnicas têm surgido com o objetivo de melhorar a produção das aves desde a postura dos ovos até o abate dos animais. Dentre essas técnicas a nutrição pré-eclosão ou in ovo é um conceito promissor que visa disponibilizar ao embrião ainda no ovo maior quantidade de nutrientes, podendo levar a um melhor desempenho dos animais após a eclosão, já que o saco vitelino, a principal fonte de nutrientes do animal recém eclodido, pode não suprir sua necessidade nutricional para bom desempenho nessa primeira fase de vida. Esta técnica pode auxiliar também na redução de descarte de pintos no momento do nascimento, pois o peso ao nascimento do pinto poderia ser aumentado, mesmo animais oriundos de matrizes mais novas que tem por características a postura de ovos menores.

O animal recém eclodido já nasce com seu trato gastrintestinal (TGI) anatomicamente completo, mas imaturo tanto morfologicamente quanto fisiologicamente, o que pode prejudicar o desempenho futuro do animal caso seu TGI não se desenvolva o mais rápido possível. Daí surge a necessidade de técnicas que vissem acelerar ao máximo essa maturação do TGI, como a nutrição específica para a fase de pós-eclosão ou pré-inicial.

$\mathrm{Na}$ alimentação pós-eclosão alguns fatores devem ser levados em consideração como: as necessidades nutricionais para essa fase de vida, que tipo de alimento deve ser utilizado já que o TGI ainda não esta totalmente desenvolvido e qual a forma de fornecimento dessa ração.

Este trabalho teve como objetivo expor as características, vantagens e desvantagens da nutrição pré e pós-eclosão em aves.

\section{2 - Composição e Estrutura do Ovo}

Um bom desenvolvimento e crescimento do embrião dependem diretamente de uma ótima composição de nutrientes no ovo (Fasenko, 2007). Os principais nutrientes do ovo são lipídios, proteínas, carboidratos e minerais 
SCOTTÁ, B.A. et al. Nutrição pré e pós-eclosão em aves. PUBVET, Londrina, V. 8, N. 8, Ed. 257, Art. 1702, Abril, 2014.

encontrados principalmente na gema e no albúmen. Na casca também encontramos uma grande quantidade de minerais, basicamente carbonato de cálcio.

O ovo da galinha contém em média de 58,5\% de albúmen, $31 \%$ de gema e 10,5\% de casca. Esses dados podem variar de acordo com a idade da ave no momento da postura e/ou a linhagem (Vieira \& Moran Jr., 1999).

A idade das matrizes influencia diretamente na composição do ovo e no tamanho dos pintinhos, sendo que poedeiras mais novas, normalmente produzem ovos menores e com menor proporção de gema do que poedeiras mais velhas. Quando se compara o peso das pintainhas originadas de ovos com o mesmo peso, mas oriundos de aves novas e velhas, aqueles oriundos de aves novas têm menor peso ao nascimento (Lara et al. 2005).

O ovo é composto pela casca, que é uma estrutura porosa constituída principalmente por carbonato de cálcio. A casca é porosa e isto faz com que haja a troca constante de gases com o ambiente externo. Aderido a esta casca, existem duas membranas, uma externa e outra interna, a externa fica aderida à casca, enquanto que a membrana interna é retraída quando o ovo esfria, formando uma câmara de ar na parte mais larga do ovo.

A clara é composta por diferentes tipos de proteína, e é denominada de albúmen. As proteínas encontradas no albúmen consistem de proteínas simples (ovoalbumina e ovotransferrina), glicoproteínas (ovomucóide e ovomucina), ovoglobulinas e lisozimas, com carboidratos em sua estrutura (Vieira \& Moran Jr., 1999).

A gema é a estrutura central do ovo, composta principalmente por lipídeos. A maior parte da matéria seca da gema ocorre na forma de lipoproteínas de baixa densidade (VLDL). A VLDL presente na gema é diferente da VLDL utilizada em outros tecidos, pois ela possui praticamente a metade do tamanho de VLDL normal e não necessita da apoproteína C para ser absorvida. Os lipídios da gema compreendem triglicerídeos $(72,5 \%)$, fosfolipídios $(24,4 \%)$ e colesterol (3,9\%) (Vieira \& Moran Jr., 1999). 
SCOTTÁ, B.A. et al. Nutrição pré e pós-eclosão em aves. PUBVET, Londrina, V. 8, N. 8, Ed. 257, Art. 1702, Abril, 2014.

À medida que a matriz fica mais velha o teor de proteína na gema aumenta, enquanto que no albúmen diminui. No topo da gema, está localizado o blastodisco, que é onde o embrião se localiza após a fertilização. Ligando a gema à base e ao topo do ovo estão as calazas ou chalazas, que agem como ligamentos com a finalidade de manter a gema horizontalmente centralizada no ovo.

\section{3 - Desenvolvimento Embrionário}

Segundo Moran (2007), o desenvolvimento embrionário na incubação pode ser dividido em três fases, o estabelecimento do embrião, a formação completa do embrião e a preparação para emersão do ovo.

A fase de estabelecimento do embrião começa com a fertilização no infundíbulo da galinha e continua com a incubação do ovo subsequente. A energia gasta neste momento pelo embrião é oriunda da glicólise do albúmen. O metabolismo do embrião neste momento é praticamente todo anaeróbico e, com isso, acumula-se lactato devido à baixa difusão de oxigênio na hemoglobina primitiva (Moran, 2007). O albúmen é um fator dominante no sucesso da transição do metabolismo do embrião de anaeróbico para aeróbico (Chistensen et al. 2001).

O sistema vascular é rapidamente estabelecido e através de invaginações começam a se formar o saco coriônico e a cavidade alantóide. Uma camada celular interna da membrana amniótica secreta fluido amniótico, no qual o embrião estará mergulhado, evitando a desidratação e protegendo-o contra choques. O córion está ao redor de todas as estruturas embrionárias e serve como membrana protetora. O alantóide cresce acompanhando o crescimento do embrião, até que se funde com o córion, formando a membrana corioalantóica, responsável pela troca de oxigênio e dióxido de carbono com o ambiente.

A segunda fase marca o completo desenvolvimento do sistema vascular, com a corioalantóide capaz de assegurar a troca de gás carbônico por oxigênio. 
SCOTTÁ, B.A. et al. Nutrição pré e pós-eclosão em aves. PUBVET, Londrina, V. 8, N. 8, Ed. 257, Art. 1702, Abril, 2014.

O uso de ácidos graxos é a principal fonte de energia para o embrião nesta fase (Sato et al. 2006) e o embrião se desenvolve muito durante essa fase.

Ácidos graxos essenciais são preservados pela síntese de membranas celulares, enquanto que ácidos graxos saturados são consumidos para satisfazer a crescente necessidade calórica, devido à formação de novos tecidos.

$\mathrm{Na}$ última fase, denominada preparação para emersão do ovo, o tamanho do embrião e seus movimentos causam ruptura da membrana que separa o albúmen do fluido amniótico, misturando-os. Segundo Klasing (1998), a partir dessa fase, o embrião começa a ingerir o líquido amniótico. Neste estágio do desenvolvimento intestinal, os enterócitos do duodeno e jejuno são capazes de absorver macromoléculas de proteína, num processo similar à absorção do colostro em mamíferos. O consumo continua até que o fluido amniótico desapareça.

Quando se completa o desenvolvimento do tecido esquelético embrionário, os nutrientes absorvidos são usados para maturação de órgãos viscerais e a maior parte deles é armazenado como glicogênio (Moran, 2007) que é depositado no fígado e músculos.

O processo de emersão começa quando a membrana corioalantóide e a membrana interna da casca próxima à camada de ar são rompidas. Esse processo é denominado internal pipping e ocorre por volta do $18^{\circ}$ dia de incubação. Neste ponto o embrião deve começar a respiração pulmonar, pois a membrana externa está perdendo contato com a casca. É um período crítico, pois o suprimento de oxigênio é limitado e impede o contínuo uso de lipídios como fonte de energia, mudando o metabolismo da glicose a partir das reservas glicogênicas novamente para anaeróbico, produzindo lactato. O saco vitelino é retraído para a cavidade abdominal e o sangue periférico é restabelecido para dentro do embrião. Uma grande quantidade de energia é utilizada para sustentar os movimentos de bicagem (pipping) para quebrar a casca e rotação do corpo. 
SCOTTÁ, B.A. et al. Nutrição pré e pós-eclosão em aves. PUBVET, Londrina, V. 8, N. 8, Ed. 257, Art. 1702, Abril, 2014.

O pintinho continua quebrando a casca (external pipping), fazendo movimentos de rotação e usando os pés para ajudar a se livrar da casca. Há uma separação de vasos sanguíneos do embrião da membrana da casca e o pintinho está livre.

\section{4 - Nutrição Pré-eclosão}

O acesso do embrião a nutrientes pode melhorar o desenvolvimento do sistema digestório (Foye et al. 2005), a eclodibilidade e o desempenho do frango. Com base nesta premissa, o conceito da suplementação de nutrientes na fase pré-eclosão, ou nutrição in ovo, foi estabelecido.

A nutrição in ovo na fase pré-eclosão é prática recente na avicultura, e por isso pouco se sabe acerca dos níveis e tipos de nutrientes que podem ser utilizados na nutrição do embrião. Um estudo que pode indicar quais nutrientes usar é o da composição do saco vitelino. O saco vitelino é a fonte primária de nutrição do pinto (Burnham et al. 2001) e contém aproximadamente, 51,7\% de proteína bruta, $32,6 \%$ de estrato etéreo, $4,8 \%$ de cinzas e pequena quantidade de carboidratos (Vieira \& Moran Jr., 1998).

\section{1 - Nutrientes a Serem Inoculados}

Diversos estudos foram realizados durante o período de incubação administrando vitaminas, aminoácidos e carboidratos in ovo buscando estimular o crescimento e aumento do peso dos pintos precocemente (Ohta \& Kidd, 2001). A alimentação do embrião, pela administração de nutrientes in ovo, pode ter efeito positivo sobre a eclodibilidade, desenvolvimento do sistema digestório, peso vivo e estado nutricional pós-eclosão, já que o acesso ao alimento é fundamental para o desenvolvimento precoce de pintos após eclosão (Uni \& Ferket, 2004).

A nutrição na fase pré-eclosão é possível, pois o embrião já possui enzimas digestivas (Sklan et al. 2003) e ingere o fluido amniótico a partir do 
SCOTTÁ, B.A. et al. Nutrição pré e pós-eclosão em aves. PUBVET, Londrina, V. 8, N. 8, Ed. 257, Art. 1702, Abril, 2014.

décimo quinto dia de incubação (Klasing, 1998), podendo promover melhor desempenho dos pintos pós-eclosão, já que maiores reservas de nutrientes estariam disponíveis para essa fase.

Embora os aminoácidos presentes na gema possam ser suficientes durante o processo de eclosão, após o nascimento, as reservas do saco vitelino da ave são insuficientes para o processo de crescimento (Ohta et al. 2004). A inoculação de aminoácidos já se mostrou viável, melhorando o peso vivo da ave por meio do aumento no conteúdo de aminoácidos no embrião (Ohta \& Kidd, 2001).

Entre os aminoácidos utilizados para inoculação, a glutamina pode exercer efeitos positivos (Maiorka, 2002), pois apresenta relação positiva entre a síntese protéica e a concentração do aminoácido (Welborne, 1995). O saco vitelino de um pinto recém-eclodido oriundo de uma ave jovem contém aproximadamente $150 \mathrm{mg}$ de glutamina (Vieira \& Moran Jr., 1998).

Pedroso et al. (2006) estudaram a inoculação in ovo de ácido linoleico, glicose e glutamina em ovos de matrizes pesadas e observaram que a inoculação desses nutrientes foi prejudicial para as características relacionadas à eclodibilidade e o desempenho dos pintos até 10 dias de idade.

Leitão et al. (2008) estudaram a inoculação de glicose em ovos de frango de corte, e concluíram que a inoculação de glicose in ovo não melhorou os parâmetros de incubação, peso ao nascer e o desempenho na fase préinicial de pintos de corte, e a dose de $0,6 \mathrm{ml}$ de glicose prejudicou a eclodibilidade. Já Uni et al. (2005) suplementaram carboidratos in ovo e observaram melhor desempenho de pintos de corte nas fases pré-inicial e inicial.

Campos et al. (2011) estudaram a inoculação de uma solução nutritiva a base de glicose e sacarose, e observaram que a inoculação de $0,5 \mathrm{ml}$ da solução nutritiva levou a uma menor taxa de eclodibilidade e maior mortalidade embrionária, as aves provenientes dos ovos não inoculados apresentaram maior consumo de ração aos 7 dias de idade, e a inoculação de $0,5 \mathrm{ml}$ de solução contendo $2,5 \%$ de glicose mais $3 \%$ de sacarose 
SCOTTÁ, B.A. et al. Nutrição pré e pós-eclosão em aves. PUBVET, Londrina, V. 8, N. 8, Ed. 257, Art. 1702, Abril, 2014.

proporcionou melhor conversão alimentar, maior ganho de peso e rendimento de peito dos frangos de corte aos 21 dias de idade.

\section{2 - Processo de Inoculação dos Nutrientes}

Em condições experimentais, antes de se iniciar o processo de inoculação de nutrientes em ovos férteis, deve ser feita a higienização dos ovos com álcool iodado ( $2 \%)$, para evitar ao máximo contaminações. A inoculação dos nutrientes deve ocorrer preferencialmente após o $15^{\circ}$ dia da incubação, pois é quando ocorre o início da absorção dos fluidos amnióticos.

A perfuração deve ser feita na região da câmara de ar, com o auxílio de uma furadeira com broca de $2 \mathrm{~mm}$ de diâmetro, evitando perfurar a membrana interna da casca do ovo. Os nutrientes são inoculados nos ovos com o auxílio de uma agulha de $7 \times 2,5 \mathrm{~mm}$ de diâmetro acoplada a uma seringa e o conteúdo é aplicado diretamente no líquido amniótico, evitando atingir o embrião. Após a inoculação o orifício da casca deve ser lacrado com parafina fundida (Gonzales et al. 2003).

Nas grandes empresas que realizam essa técnica, a forma de aplicação é a mesma usada para a aplicação de vacinas in ovo, por um método conhecido como inject.

\section{5 - Nutrição Pós-eclosão}

O período de transição de embrião para o estágio pós-eclosão é crítico para o desenvolvimento de todos os sistemas nas aves. Desta forma algumas técnicas de manejo durante os primeiros dias de vida podem melhorar o desempenho da ave durante todo o seu ciclo produtivo. Em particular, o trato gastrintestinal (TGI), que apesar de já estar anatomicamente completo no final do período de incubação, sofre algumas alterações que preparam a ave para o consumo e utilização de alimentos. 
SCOTTÁ, B.A. et al. Nutrição pré e pós-eclosão em aves. PUBVET, Londrina, V. 8, N. 8, Ed. 257, Art. 1702, Abril, 2014.

\section{1 - Desenvolvimento do Trato Gastrintestinal}

No momento da eclosão, o sistema digestório já se encontra anatomicamente formado (Overton \& Shoup, 1964), mas sua capacidade funcional ainda está imatura quando comparado à de aves adultas. Assim após a eclosão, o TGI sofre grandes alterações, como a maturação funcional do intestino, as quais envolvem mudanças morfológicas e fisiológicas, que proporcionam um aumento na área de digestão e absorção.

As alterações morfológicas mais evidentes são o aumento no comprimento do intestino, na altura e densidade das vilosidades, no número de enterócitos, células caliciformes e células enteroendócrinas (Baranyiova \& Holman, 1976). Já as alterações fisiológicas, estão relacionadas com o aumento na produção e atividade de enzimas digestivas pancreáticas e de membranas (Nitsan et al. 1991).

As enzimas digestivas de maneira geral, já estão presentes no TGI do embrião, entretanto a presença de substrato parece induzir uma maior produção destas enzimas. Sendo assim, a atividade das enzimas digestivas, tanto pancreáticas quanto de membrana aumentam com a idade da ave, atingindo níveis mais elevados, em média, aos 10 dias de idade. Nitsan et al. (1991) afirmaram que aves recém eclodidas possuem uma reserva de enzimas pancreáticas, produzidas durante o crescimento embrionário, porém, estas reservas são insuficientes para hidrolisar os substratos no lúmen e manter a concentração inicial, de forma que estas diminuem rapidamente logo após a eclosão.

Nir et al. (1993) afirma que a atividade enzimática no TGI, durante a primeira semana de vida, pode limitar a digestão e, consequentemente, o crescimento de frangos de corte. Sklan et al. (2003) descreveram que, apesar de estudos indicarem que as enzimas pancreáticas estão presentes no intestino delgado das aves ainda no estágio embrionário, o consumo de alimento desencadeia a secreção constante de amilase e tripsinogênio. 
SCOTTÁ, B.A. et al. Nutrição pré e pós-eclosão em aves. PUBVET, Londrina, V. 8, N. 8, Ed. 257, Art. 1702, Abril, 2014.

Os fatores que interferem no desenvolvimento de TGI são a genética e a ingestão e digestão de alimentos, ou seja, a presença do alimento. Geneticamente o desenvolvimento do TGI pode variar nas diferentes linhagens de aves. Nir et al. (1993) compararam o crescimento alométrico do TGI de frangos de corte e poedeiras e demonstraram que o intestino delgado e fígado foram maiores em frangos de corte que em poedeiras, no entanto o pâncreas mostrou relação inversa.

Já sobre a presença de alimento, a qualidade e a quantidade de alimento também parecem influenciar no desenvolvimento do TGI. A redução no consumo de alimento causada pela exposição crônica de frangos de corte a $35^{\circ} \mathrm{C}$ pode determinar numa redução do peso e comprimento do intestino delgado, bem como nas características das vilosidades. Também ocorrem consideráveis variações no comprimento do TGI, de acordo com o tipo de alimentação. Maiorka et al. (2000) observaram que o comprimento do duodeno e o peso do duodeno, jejuno e íleo foram influenciados beneficamente pelo arraçoamento $24 \mathrm{~h}$ após a eclosão.

\section{2 - Níveis Nutricionais}

As exigências nutricionais das aves variam de acordo com a idade. Assim, à medida que a ave fica mais velha, ocorre aumento do consumo, ao mesmo tempo em que há redução do percentual de cada nutriente na ração. $\mathrm{A}$ divisão do programa de alimentação em várias rações faz com que as aves tenham uma alimentação o mais próximo possível da sua real necessidade nutricional.

As aves, nos primeiros dias de vida, possuem uma alta taxa de crescimento e esta taxa vai diminuindo com o aumento da idade, até atingir pleno desenvolvimento do tecido. Desta forma é observado que logo após o nascimento, há maior deposição de tecido muscular do que de tecido adiposo e esta relação vai sendo alterada à medida que a ave vai ficando mais velha. 
SCOTTÁ, B.A. et al. Nutrição pré e pós-eclosão em aves. PUBVET, Londrina, V. 8, N. 8, Ed. 257, Art. 1702, Abril, 2014.

Assim, é de se esperar que as exigências nutricionais na primeira semana de vida das aves sejam maiores, por causa da maior taxa de crescimento.

\section{3 - Tipos de Ingredientes}

O fornecimento de ração o mais rápido possível após a eclosão é uma saída interessante para favorecer o desenvolvimento do sistema digestivo. Penz Jr. \& Vieira (1998), sugerem que a presença de enzimas ativas não depende somente da idade das pintainhas, mas também do processo de alimentação com dietas sólidas.

Uma vez que o sistema enzimático não está totalmente desenvolvido, alimentos que aumentem a viscosidade intestinal não devem ser utilizados para pintos na primeira semana de vida, pois estes levam a uma redução da digestibilidade e, consequentemente, redução no desempenho dos pintos. Bedfod et al. (1996) citam que a viscosidade reduz a difusão de nutrientes e com isso a taxa de absorção. Alimentos como trigo, cevada e centeio, não devem ser utilizados nesta fase de vida, pois possuem como característica a capacidade de aumentar a viscosidade intestinal, pois são ricos em polissacarídeos não amiláceos solúveis ou PNAs.

É importante também avaliar a utilização de óleos e gorduras nas rações pré-iniciais, pois as aves nessa fase de vida não digerem de forma adequada os lipídios. Assim, a utilização de altos níveis de óleo ou gorduras nas rações, não será muito eficiente sobre o desempenho dos animais. Mas, a suplementação de óleo em níveis baixos pode ter efeito benéfico por diminuir a pulverulência e melhorar a palatabilidade da ração.

O farelo de glúten de milho geralmente é usado na formulação de ração para pintos na primeira semana de idade. Ele possui como características principais ter altos teores de proteínas, energia metabolizável aparente e de aminoácidos sulfurosos, mas apresenta baixo teor de lisina. 
SCOTTÁ, B.A. et al. Nutrição pré e pós-eclosão em aves. PUBVET, Londrina, V. 8, N. 8, Ed. 257, Art. 1702, Abril, 2014.

\section{4 - Granulometria da Dieta}

Os ingredientes das rações, principalmente os cereais, antes de serem utilizados são moídos, de forma a garantir que os nutrientes presentes estejam numa forma mais disponível para os animais. Os nutricionistas têm preferência por ingredientes finos e uniformemente moídos, na expectativa deles serem mais facilmente digeridos. Entretanto, partículas muito finas geralmente grudam no bico das aves, reduzindo o consumo e aumentando o desperdício.

Por outro lado, as aves têm certa preferência pelo tamanho da partícula, em função do tamanho do bico, aves mais velhas preferem partículas maiores, e esta preferência pode fazer com que os animais selecionem as partículas que irão consumir, levando a um desbalanceamento nutricional, causado pelo consumo diferenciado dos nutrientes.

Uma saída para o problema da seleção de partículas é a peletização. Segundo Gadient (1986), o processo de peletização tem como vantagens, além da melhoria na digestibilidade, o aumento da densidade física da ração, a possibilidade de uso de ingredientes com baixa palatabilidade, redução do desperdício e facilidade de transporte. Mas, o processo de peletização pode causar danos à estabilidade das vitaminas, em função do calor, pressão e umidade utilizados para o processamento.

Bertechini et al. (1991), comparando o desempenho de pintos de um a 28 dias, alimentados com ração peletizada ou farelada, encontraram melhor desempenho em aves que receberam ração peletizada ( $2 \mathrm{~mm}$ de diâmetro) quando comparadas com aves que receberam ração farelada.

\section{6 - Conclusão}

A nutrição pré-eclosão ou in ovo, mesmo sendo um conceito promissor, apresenta resultados controversos, talvez devido à técnica de aplicação dos 
SCOTTÁ, B.A. et al. Nutrição pré e pós-eclosão em aves. PUBVET, Londrina, V. 8, N. 8, Ed. 257, Art. 1702, Abril, 2014.

nutrientes ou devido aos nutrientes aplicados ou ainda aos níveis de aplicação, sendo necessário que mais trabalhos sejam realizados nessa área.

A nutrição pós-eclosão tem se mostrado eficiente na maturação precoce do trato gastrintestinal (TGI) que mesmo já nascendo anatomicamente completo, o rápido acesso a alimentação sólida acelera o processo de maturação, levando a uma rápida evolução dos enterócitos e maior produção enzimas digestivas.

Portanto o rápido acesso da pintainha ao alimento é essencial. Além disso, deve ser considerada também a granulometria da ração e sua forma física, pois há influencia positiva no desempenho dos animais recém eclodidos. Os bons resultados desta técnica persistem durante todo o ciclo produtivo do animal, melhorando de forma significativa seu desempenho.

\section{7 - Referências Bibliográficas}

BARANYIOVA, E. \& HOLMAN, J. Morphological changes in the intestinal wall in fed and fasted chickens in the first week after hatching. Acta Vet. Brno., v.45, p.151-158, 1976.

BEDFORD, M.R. Interaction between ingest fed and the system in poultry, J. Appl. Poult. Res., v.5, p.86-95. 1996.

BERTECHINI, A.G.; ROSTAGNO, H.S.; FONSECA, J.B. et al. Efeitos da forma física e nível de energia da ração sobre o desempenho e carcaça de frangos de corte. Revista Brasileira de Zootecnia v.20, p.229-240, 1991.

BURNHAM, M.R.; PEEBLES, E.D.; GARDNER, C.W. et al. Effects of incubator humidity and hen age on yolk composition in broiler hatching eggs from young breeders. Poultry Science, v.80, n.10, p.1444-1450, 2001.

CAMPOS, A.M.A; ROSTAGNO, H.S.; GOMES, P.C. et al. Efeito da inoculação de soluções nutritivas in ovos sobre a eclodibilidade e o desempenho de frangos de corte. Revista Brasileira de Zootecnia, v.40, n.8, p.1712-1717, 2011.

CHRISTENSEN, V.L.; WINELAND, M.J.; FASENKO, G.M. et al. Egg storage effects on plasma glucose and supply and demand tissue glycogen Concentrations of broiler embryos. Poultry. Science. v.80 p.1729-1735, 2001.

FASENKO, G.M. Egg Storage and the Embryo. Poultry Science. v.86, p.1020-1024, 2007.

FOYE, O.; FERKET, P.; UNI, Z. et al. The effects of in ovo feeding of protein and beta-methylbeta hidroxybutyrate (HMB) on nutrient digestion and absorption in neonatal turkey poults. In: INTERNATIONAL POULTRY SCIENTIFIC FORUM, 2005, Atlanta. Abstracts... Atlanta: Poultry Science Association, 2005.

GRADENT, M. Effect of pelleting on nutritional quality of feed. Maryland nutrition conference for feed manufactures. Proceedings..., p. 73-79. 1986. 
GONZALES, E.; OLIVEIRA, A.S.; CRUZ, C.P. et al. In ovo supplementation of 25(OH)D3 to broiler embryos. In: EUROPEAN SYMPOSIUM ON POULTRY NUTRITION, 2003, Lillehammer. Proceedings... Lillehammer: Science Association, p.72-74, 2003.

KLASING, K.C. Amino acid. In: Comparative avian nutrition. Wallingford, UK: CAB International. p.133-170, 1998.

LARA, L.J.C.; BAIÃO, N.C.; CANÇADO, S.V.; et al. Influência do peso inicial sobre o desempenho e o rendimento de carcaça e cortes de frangos de corte. Arquivo Brasileiro de Medicina Veterinária e Zootecnia, v.57, n.6, p.799-804, 2005.

LEITÃO, R.A.; LEANDRO, N.S.M.; CAFÉ, M.B. et al. Inoculação de glicose em ovos embrionados de frangos de corte: parâmetros de incubação e desempenho inicial. Ciência Animal Brasileira, v.9, n.4, p.874-855, 2008.

MAIORKA, A. Efeitos da idade a matriz, do jejum, da energia da ração e da glutamina sobre o desenvolvimento da mucosa intestinal e atividade enzimática do pâncreas de pintos de corte. Jaboticabal: Universidade Estadual Paulista, 2002. 103p. Tese (Doutorado em Zootecnia) Universidade Estadual Paulista, 2002.

MAIORKA, A.; SANTIN, E.; FISCHER DA SILVA, A.V. et al. Desenvolvimento do trato gastrintestinal de embriões oriundos de matrizes pesadas de 30 a 60 semanas de idade. Revista Brasileira de Ciência Avícola, v.2, p.141-144, 2000.

MORAN JR, Nutrition of the Developing Embryo and Hatchling. Poultry Science, v.86 p.10431049, 2007.

NIR, I.; NITSAN, Z.; MAHAGNA, M. Comparative growth and development of the digestive organs and some enzymes in the broiler chicks and egg type chicks after hatching. Brit. Poult. Sci., v.34, p.523-532, 1993.

NITSAN, Z.; BEM-AURAHAM, G.; ZOREF, Z. et al. Growth and development of the digestive organs and some enzymes in the broiler chicks after hatching. Brit. Poult. Sci., v.32, p.515$523,1991$.

OHTA, Y.; YOSHIDA, T.; TSUSHIMA, N. et al. Comparison between broilers and layers for growth and protein use by embryos. Poultry Science, v.83, n.5, p.783-787, 2004.

OHTA, Y. \& KIDD, M.T. Optimum site for in ovo amino acid injection in broiler breeder eggs. Poultry Science, v.80, n.10, p.1425-1429, 2001.

OVERTON, J. \& SHOUP,J. Fine structure of cell surface specializations in the duodenal mucosa of the chick. J. Cell Biol., v.21, p. 75-82, 1964.

PEDROSO, A. A.; BARBOSA, V. T.; CAFÉ, M. B.; et al. Mortalidade de embriões de matrizes pesadas submetidos à injeção in ovo de glicose. In: CONFERÊNCIA APINCO DE CIÊNCIA E TECNOLOGIA AVÍCOLAS, 2006. Campinas. Anais... Campinas: Fundação APINCO de Ciência e Tecnologia Avícolas, 2006.

PENZ JR, A.M. \& VIEIRA, S.L. Nutrição na primeira semana. Conf. Apinco 98 de Ciência e Tecnologia Avícola. Anais... FACTA. p. 121-139. 1998.

SATO, M.; TACHIBANA, T.; FURUSE, M. et al. Heat production and lipid metabolism in broiler and layer chickens during embryonic development. Comp. Biochem. Physiol. v.143, p.382388, 2006.

SKLAN, D.; GEYRA, A.; TAKO, E. et al. Ontogeny of brush border carbohydrate digestion and uptake in the chick. British Journal of Nutrition, v.89, n.6, p.747-753, 2003.

UNI, Z.; FERKET, P.R.; TAKO, E. et al. In ovo feeding improves energy status of late-term chicken embryos. Poultry Science, v.84, n.5, p.764-770, 2005. 
UNI, Z. \& FERKET, R. P. Methods for early nutrition and their potential. World's Poultry Science Journal, v.60, p.101-111, 2004.

VIEIRA, S.L. \& MORAN JR., E.T. Effects of egg of origin and chick post-hatch nutrition on broiler live performance and meat yields. World's Poultry. Science., v.55, p.125-142, 1999.

VIEIRA, S.L. \& MORAN JR, E.T. Eggs and chicks from broiler breeders of extremely different age. Journal of Applied Poultry Research, v.7, n.2, p.372-376, 1998.

WELBORNE, T.C. Increased plasma bicarbonate and growth hormone after an oral glutamine load. American Journal of Clinical Nutrition, v.61, n.5, p.1058-1061, 1995. 